\title{
Adversity, Adaptive Calibration, and Health: The Case of Disadvantaged Families
}

\author{
Tomás Cabeza de Baca ${ }^{1} \cdot$ Richard A. Wahl ${ }^{2}$. \\ Melissa A. Barnett ${ }^{3}$ - Aurelio José Figueredo ${ }^{4}$. \\ Bruce J. Ellis ${ }^{3}$
}

Received: 8 September 2015 / Revised: 17 January 2016 / Accepted: 21 January 2016 /

Published online: 1 February 2016

(C) Springer International Publishing 2016

\begin{abstract}
Epidemiologists and medical researchers often employ an allostatic load model that focuses on environmental and lifestyle factors, together with biological vulnerabilities, to explain the deterioration of human physiological systems and chronic degenerative disease. Although this perspective has informed medicine and public health, it is agnostic toward the functional significance of pathophysiology and health deterioration. Drawing on Life History (LH) theory, the current paper reviews the literature on disadvantaged families to serve as a conceptual model of stress-health relationships in which the allocation of reproductive effort is instantiated in the LH strategies of individuals and reflects the bioenergetic and material resource tradeoffs. We propose that researchers interested in health disparities reframe chronic degenerative diseases as outcomes resulting from strategic calibration of physiological systems to best adapt, survive, and reproduce in response to demands of specific developmental contexts. These effects of adversity on later-age degenerative disease are mediated, in part, by socioemotional and cognitive mechanisms expressed in different life history strategies.
\end{abstract}

Tomás Cabeza de Baca

tomas.cabezadebaca@ucsf.edu

1 Health Psychology, Department of Psychiatry, University of California, San Francisco, 3333 California Street, Suite 465, San Francisco, CA 94118, USA

2 Director, Adolescent Medicine, Department of Pediatrics, College of Medicine, University of Arizona, Tucson, AZ 85721, USA

3 Division of Family Studies and Human Development, Norton School of Family and Consumer Sciences, University of Arizona, Tucson, AZ 85721, USA

4 Department of Psychology, School of Mind, Brain, and Behavior, College of Science, University of Arizona, Tucson, AZ 85721, USA 
Keywords Life history theory - Chronic degenerative disease - Evolutionary psychology. Harshness · Unpredictability · Stress · Adversity · Disadvantaged families .

Unpredictability schema

In this review, we closely examine processes in disadvantaged families to serve as a conceptual model of stress-health relationships in which the allocation of reproductive effort is regulated by the varying life history (LH) strategies of individuals and reflects the bioenergetic and material resource tradeoffs specified by those evolved adaptive strategies. The conceptualization of LH tradeoffs is a powerful heuristic tool that can be used to generate unique hypotheses regarding the allocation of energy toward features of ontogeny (e.g., birth weight, age at menarche) and the behavioral and psychological implications associated with such allocations. Despite the research advances within developmental and epidemiological research investigating health disparities among disadvantaged groups, we suggest that new advances in these fields will occur if researchers consider chronic degenerative diseases as the result of strategic physiological calibration of systems to best adapt, survive, and reproduce in response to demands from specific developmental contexts.

We propose that the application of life history theory will generate novel predictions regarding the mediating pathways through which variation in longevity and degenerative diseases during senescence represent the consequences of relevant conditional adaptations to environmental conditions over development. By explicitly considering the implications of diversity in human life history strategies in understanding human degenerative diseases, we reframe physiological dysregulation and pathology as the result of selective physiological "investments" and "tradeoffs" in the service of survival and reproduction over the life course, and not as the direct result of exogenous adversity, as is often done. Previous applications of LH theory within the developmental sciences has allowed for the generation and empirical confirmation of novel and integrative hypotheses about health and disease that are truly crossdisciplinary (e.g., Del Giudice et al. 2011; Ellis and Del Giudice 2014; Ellison and Jasienska 2007; Gluckman et al. 2011; Kuzawa and Quinn 2009; McDade 2003; Nettle et al. 2013). The present review examines the special case of disadvantaged families to articulate how contextual factors such as socioecological stressors may alter cognitive schemas, socioemotional functioning, reproductive behaviors, and, ultimately, longevity.

We begin by reviewing relevant principles from LH theory. We then reconsider the well-established effects of social and ecological stressors on chronic degenerative disease and longevity as the observed empirical phenomena and reinterpret them in terms of LH theory. Next we examine disadvantage families and their household and contextual processes to serve as an application of LH theory to research on stress-health relationships and reproductive effort. Finally, we provide a summary and integration of the previous sections, and we consider some possible opportunities for medical and psychosocial intervention that might help prevent or protect against some of the health disparities stemming from adverse consequences of reproductive effort on long-term health. 


\section{Life History Theory}

LH theory (Charnov 1993; Roff 1992; Stearns 1992) is an evolutionary theory used to explain between- and within-species differences in how individuals adapt their physiology and behavior to different ecological conditions. Individual organisms possess a finite amount of time, energy, and resources that they can allocate toward specific facets of development: growth, survival, and reproduction. Thus, individuals are selected to make tradeoffs that prioritize investment in specific facets of development, so that greater investment of time and/or resources in one domain occurs at the expense of investment in competing domains. For example, resources spent on an inflammatory host response to fight infection cannot be spent on reproductive effort. The benefits of an inflammatory host response are traded off against the costs of lower ovarian function in women and reduced musculoskeletal function in men (Clancy et al. 2013; Muehlenbein and Bribiescas 2010). These tradeoffs, which track both internal conditions and external environments, function to maximize fitness - survival and reproduction - within the specific ecology in which the organism is developing and in relation to the organism's phenotypic condition (e.g., Bjorklund and Ellis 2014; Rickard et al. 2014).

A central intra-individual LH tradeoff is between somatic effort, which consists of the costs of maintenance and growth of the organism (i.e., all of the bioenergetic resources devoted to growing the brain and body and delaying mortality), and reproductive effort, the "costs of reproduction" the organism incurs. Reproductive effort is further broken down between mating and parenting. Again, devoting energy in one area of development usually requires more energetic resources allocated away from other areas of development. These tradeoffs are instantiated in critical decisions over the life course, such as earlier versus later reproduction and quantity versus quality of offspring, that define alternative developmental pathways, or life history strategies (Ellis et al. 2009; Stearns et al. 2008).

Different life history strategies encompass integrated suites of behavioral, psychological and physiological traits that vary along a dimension of fast versus slow (e.g., Del Giudice et al. 2015). As reviewed in Ellis et al. (2009); Del Giudice et al. (2015), and Figueredo et al. (2006, 2013), Fast life history strategies are comparatively high risk and present oriented (taking benefits opportunistically with little regard for longterm consequences), prioritize mating effort (e.g., competitive risk-taking, aggression), are characterized by earlier ages of sexual development and reproduction, and focus on producing of a greater number of offspring with less investment of resources, time, and energy in each. By contrast, slow life history strategies are comparatively long-term oriented and low risk (e.g., longer time horizons, more delay of gratification, better selfregulation and behavioral control), are characterized by later timing of sexual development and reproduction, and focus on producing a smaller number of offspring and investing heavily in each of them.

Life history theory and research suggest that individuals oriented toward a faster life history strategy devote less energy toward maintaining their health or growth in comparison to those with a slower life history strategy (Brumbach et al. 2009; Ellis and Del Giudice 2014; Figueredo et al. 2004; Figueredo et al. 2007; Figueredo and Rushton 2009). Thus, tradeoffs between somatic effort and reproductive effort contribute to physiological and behavioral characteristics that collectively define life history 
strategies. As a species, humans are generally oriented toward a slow LH strategy (Del Giudice et al. 2015), that includes altricial births, long childhoods, high parental effort, and long lifespans.

The two main components of somatic effort, maintenance and growth, are selectively salient depending on the developmental stage and condition of the organism. For instance, during infancy, maintenance (e.g., allocation of nutritional energy toward development of immune function) is in direct competition with growth (e.g., allocation of nutritional energy toward increasing in size; McDade 2003, 2005). If the infant is nutritionally deprived, priority must be placed on the facet of somatic effort most important to infant survival within the ecology. In this case, the infant's body size is reduced. Although this nutrient-conserving reduction may be associated with insulin resistance and nephron-deficient kidneys that predispose lower-birthweight individuals toward metabolic syndrome and renal failure, it may also reserve metabolic resources for brain growth (Hales and Barker 1992; Kuzawa and Quinn 2009). During childhood, broadly, brain-derived glucose demands account for approximately $66 \%$ of an individual's resting metabolic rate, with peak glucose demands peaking at age 5 (Kuzawa et al. 2014). At peak brain development in childhood, body growth decelerates. Thus, immediate needs are prioritized, with potential long-term implications for the organism.

Growth and maintenance associated with somatic effort are essential for organism survival; however, for an organism to propagate its genetic lineage, it must reproduce. Reproductive Effort consists of mating effort, whereby the organism must seek, compete with rivals, maintain, and copulate with a sexual partner. Parental effort consists of gestating, caring, feeding, and protecting and caring for offspring. Differences between the sexes affect the strategies pursued toward mating versus parenting (Trivers 1972). According to Trivers (1972), large physiological minimal investment biases females toward greater selectivity in choosing mates and higher ongoing parental investment in extant offspring. Recent theorists have extended Trivers' (1972) model to include contextual factors such as adult and operation sex ratio (discussed and defined later in our paper) that impact mating opportunities and paternity certainty (Geary 2000; Kokko and Jennions 2008). We next discuss contextual factors that impact life history strategies, broadly.

\section{Environmental Stressors}

The key dimensions of the environment that regulate development of life history are availability of resources, extrinsic morbidity-mortality (i.e., external sources of disability and death that are relatively insensitive to the adaptive decisions of the organism), and predictability of environmental change (Ellis et al. 2009). Energetic resourcescaloric intake, energy expenditures, and related health conditions - set the baseline for development, slowing growth and delaying sexual maturation and reproduction under energetic stress (i.e., favoring a slow life history strategy). As reviewed in Ellis et al. (2009), when bioenergetic resources are adequate to support growth and development, cues to extrinsic morbidity-mortality and unpredictability gain importance. In this context, LH theory predicts that individuals will respond to extrinsic morbiditymortality cues (e.g., exposures to violence, premature disability and death of people around you) and unpredictability (e.g., stochastic changes in ecological context, 
resource availability, family composition) by entraining faster life history strategies (see Belsky et al. 2012; Brumbach et al. 2009; Doom et al. 2015 and Simpson et al. 2012, for supporting longitudinal data). Developmental models based on LH theory emphasize that these ecological factors tend to operate indirectly on children through more proximal processes, including those mediated by family processes (e.g., harsh parental discipline vs. warm and supportive parenting behaviors, family chaos vs. routines). For example, parental investment can buffer the impact of extrinsic mortality cues, or heighten controllability or predictability by providing a stable caregiving environment (e.g., Szepsenwol et al. 2015). Indeed, much of the effect of "toxic stress" on children's development works through the mechanism of both exposure and failure of supportive parental relationships to buffer the child from stress exposure (Shonkoff and Bales 2011).

Environmental harshness within Western populations has been typically operationalized as low socioeconomic status - whereby low socioeconomic status is associated with higher extrinsic morbidity/mortality at all ages (Belsky et al. 2012). Higher levels of adult extrinsic morbidity/mortality should orient men and women to allocate energy toward reproduction and minimize somatic investment in order to quickly reproduce before they succumb to death or illness (Belsky et al. 1991; Ellis et al. 2009). Ecological conditions that vary unpredictably do not provide organisms with reliable gauges of the environment. In these conditions, an organism should instead seek strategies that optimize fitness by reproducing earlier and, as a consequence of a strategy that maximizes reproductive effort, potentially shortening the length of life (Belsky et al. 1991; Ellis et al. 2009). A considerable amount of evolutionarydevelopmental research employing LH theory has focused on early pubertal timing as an indicator of a fast strategy (Belsky et al. 1991; Ellis 2004). Conducted in Western societies, this research has tended to focus on proximal family factors and processes (which presumably mediate larger ecological factors) such as father absence, parental warmth, and inter-parental conflict. In well-nourished Western samples, exposures to family adversity (e.g., high conflict, low parental warmth and investment, father absence) tends to be associated with earlier pubertal development (reviewed in Ellis 2004, 2013; Belsky 2012) and early onset of sexual activity, higher number of sexual partners, and higher rates of adolescent pregnancy (e.g., Ellis et al. 2003; Wight et al. 2006). Within this context, the effects of sexual abuse on LH strategies has received increasing attention. Vigil et al. (2005) have argued that sexual abuse in childhood may provide victims of abuse with cues that they are living in an environment where "reduced parental or kinship investment" resulted in "failure to protect the girl from sexual exploitation" (p. 554). They found that adverse experiences of childhood sexual abuse were associated with an accelerated reproductive strategy in women (earlier age of menarche, sexual debut, first birth, and earlier desire and readiness for children; see also Mendle et al. 2015).

\section{Sociocognitive Mediators and/or Outcomes of Ecological Stressors}

Sociocognitive functioning may be defined as the development of cognitive schemata to serve as heuristics in guiding behavior to be able to navigate adaptively through the unique social contingencies encountered in any particular social ecology. Different social and ecological "landscapes" should produce varying suites of behavior, such as 
antagonistic vs. mutualistic social schemata. Functionally, the reason for the two distinct suites of behaviors resides in the assumptions of conspecific behavior within the ecology. For example, in contexts (like harsh but predictable environments) that produce slow life history strategists, we should expect to see prosocial and cooperative behaviors reflecting convergent interests, meaning that individuals must cooperate with conspecifics to successfully acquire resources. Consequently, behavior of slow life history strategists is mutualistic or interpersonally-oriented, meaning that slow life history strategists behave in a manner that would be defined as "socially competent" or "prosocial" which involves successfully navigating, negotiating, and cooperating with conspecifics to extract resources from the environment (Gladden et al. 2013).

This emergence of prosocial functioning is because stable, predictable, and controllable environments present humans with different affordances, such as for long-term cooperation towards common fitness-enhancing goals. Stable ambient ecologies give rise to stable human societies, meaning stable interpersonal relations that provide conditions favoring mutualism, reciprocity, and other forms of altruistic, prosocial behaviors based on mutual trust and interdependence (including long-term pair-bonding among romantic partners, cooperative and shared parenting of offspring, and family formation; see Geary and Flinn 2001). Due to decreased extrinsic morbidity and mortality, populations within such ecologies tend to reach the carrying capacity of their environments, and these population-dense social ecologies require a higher mastery of social skills to navigate successfully. Under such socioecological conditions, human babies should therefore preferentially allocate their developmental resources toward somatic maintenance and growth, especially sufficient brain growth (Alexander 1974; Flinn 2006) to enable the acquisition of the necessary social skills to achieve social success among one's conspecifics (Darwin's “approval of one's fellows," as a means of survival and reproduction in the context of human society).

Thus, these non-zero-sum socioecological affordances favor the development of mutualistic social-cognitive schemata and mutualistic social strategies (Figueredo and Jacobs 2010), simply because they can yield a long-term fitness "profit" in such environments. An individual human developing within such a supportive and cooperative social ecology also internalizes these conditions as social cognitions that serve as the fundamental heuristics directing social behavior and social development, leading to further elaboration and extension of cooperative social networks in a "virtuous" rather than "vicious" cycle.

Although some might argue that in the long run such providential behaviors are ultimately more beneficial for everyone generally, the main "take-home" message of a life history approach to understanding the effects of different social ecologies is that these purported benefits are only available where there is a long run that an individual can realistically expect to live to see and eventually profit from. The empirical literature is also clear on this point. Research on executive functioning, a construct associated with regulatory/inhibitory behaviors and prefrontal functioning, has established that the association between life history and empathy is mediated by executive functioning; slower life history increases executive functioning, which increases empathy (Figueredo et al. 2012). In a sample of young women, slow life history strategy was associated with enhanced executive functions (permitting greater impulse control, more prudent long-term planning, and improved judgment and decision-making) and increased emotional intelligence (enhanced ability to understand and manage one's own 
emotions as well as the emotional states of others), which, in turn, contributed to the suppression of preferences for short-term mating strategies, and instead fostered the development of preferences for long-term romantic relationships (Figueredo et al. 2012). Related cross-sectional and longitudinal studies (Olderbak and Figueredo $2009,2010)$ have indeed shown that slow life history strategies are significant predictors of long-term relationship satisfaction and long-term pair-bond stability (nondissolution of romantic relationships).

Conversely, if the environment is both harsh and unpredictable, the collective behavior will be divergent, meaning that conspecifics will have individual and divergent interests in acquiring resources (Belsky et al. 1991; Ellis et al. 2009; Gladden et al. 2013). Behaviorally, a fast LH strategist who resides in a harsh and unpredictable environment would pursue a behavioral strategy defined as opportunistic or antagonistic (Belsky et al. 1991; Gladden et al. 2013) which includes the use of aggressive, hostile, and impulsive behavior to successfully extract resources from one's ecology and from conspecifics. An antagonistic behavioral strategy should be enacted by schemas and a worldview that conspecifics and the environment is unreliable (Ross and Hill 2002). Recent evidence suggests that low-investing maternal parenting predicted greater perceptions of unpredictability in middle childhood (Cabeza de Baca et al. 2016). Prior experience with violent events also appears to increase risk perceptions of future hazardous events in adults (Blum et al. 2014) and post-traumatic stress symptomatology in children (Garfin et al. 2014). In addition to exposure to disasters, having high conflict with a caregiver also increased PTSD symptomatology (Garfin et al. 2014).

\section{Socioemotional Mediators and/or Outcomes of Ecological Stressors}

Socioemotional functioning is defined as the constellation of affective dispositional traits that produce specific behaviors in varying contexts, evoking behavior among conspecifics (e.g., cooperative behavior or conflictual behavior). Taylor et al. (2011) assert that emotional functioning and psychosocial resources, which broadly includes social skills that are necessary to successfully negotiate and navigate one's ecology, mediates the association between early childhood adversity and physiological senescence. The model presented by Taylor et al. (2011) posits that childhood exposure to ecological adversity shapes the physiological systems to function for the "here-andnow," discounting future functioning. Life history models (e.g., Ellis et al. 2009, 2013) propose that these costs to future functioning induced by immediate needs may be part of a cohesive and coordinated strategy based on resource allocation in salient facets of development necessary for survival and reproduction. Utilizing both the model presented by Taylor et al. (2011) and life history theory, physiological calibration to ecological cues contributes to behavior that is conditionally adaptive to the organism's environment (Belsky et al. 1991; Del Giudice et al. 2011).

Further, these dispositional traits and social abilities lead the individual to seek specific organism-directed situations and environments. For instance, an individual high in hostility and with poor social skills may react more negatively in certain situations than individuals low on hostility and with good social competence, evoking negative behavior from conspecifics. Additionally, a hostile individual might seek certain situations and niches that an individual low on hostility would not seek. 
Given that life history strategies are coordinated, we should see different patterns of socioemotional and sociocognitive behavior emerge based on the life history strategy employed by the individual. Research indeed finds behavioral variation among slow and fast life history strategists. Specifically, mutualistic strategies, including emotional intelligence and executive functioning, converged with other behavioral indicators of slow life history (Gladden et al. 2013). Taken together, these findings support the hypotheses derived from life history: slow life history strategists will be less impulsive and more emotionally attuned to conspecifics to maximize cooperation and acquisition of resources. Mapping onto mutualistic and antagonist social strategies, researchers recently found that the type of pleasure an individual seeks is correlated with markers of health (Fredrickson et al. 2013). Distinctions have been made between hedonic pleasure, defined as "individual's positive affective experiences," with eudaemonic pleasure, defined as pleasure that strives "toward meaning and a noble purpose beyond simple self-gratification" (Fredrickson et al. 2013, p. 1). Hedonic pleasure could be conceptualized as more antagonistic than eudaemonic pleasure because it 'emphasizes self-interests more than mutualistic, collective goal-seeking behavior. Fredrickson et al. (2013) reported that hedonic pleasure was positively associated with up-regulation of the "conservational transcriptional response to adversity" (CTRA) suite of genes that increase pro-inflammatory response and decrease antiviral response. Conversely, the CTRA genetic profile was down-regulated in individuals high on eudaemonic pleasure.

\section{The Interplay Among Multiple Stressors: The Case of "Disadvantaged Families"}

We now examine disadvantaged families as specific examples of how systematic environmental impoverishment (harshness and unpredictability) produces a cascade of consequences that result in predictable patterns of reproductive effort. This constellation of "risk factors" is often merely presented as a list of different dimensions of socioeconomic disadvantage. Instead, we have presented them as a series of cumulative causal influences that reflect the mediating mechanisms proposed by adaptive calibration models of life history strategy, in the hopes of better elucidating why these patterns of adversity are so highly correlated with each other. Figure 1 shows our working conceptual schematic, with each hypothesized pathway of causal influence numerically coded to the sequentially ordered variables for ease of reference throughout the text that follows. Thus, in a section that examines the effect of Economic Scarcity and Harshness (Variable 1) upon Excess Criminality and Incarceration (Variable 4), we would have the parenthetic reference " $p 41$ " using the standard path-analytic notation for the hypothesized causal link, indicating the influence on Variable 4 originating from Variable 1.

We begin by discussing the ecological stressors experienced by poor, ethnic minority families, providing a case study of living in harsh, unpredictable environments. As per LH theory, this leads through a series of steps into the cognitive and behavioral manifestations of a fast LH strategy (e.g., divergent, exploitative, antagonistic social strategies), into the biodemographic markers of a fast LH strategy (e.g., early age at first birth, more offspring with lower parental investment per child). 


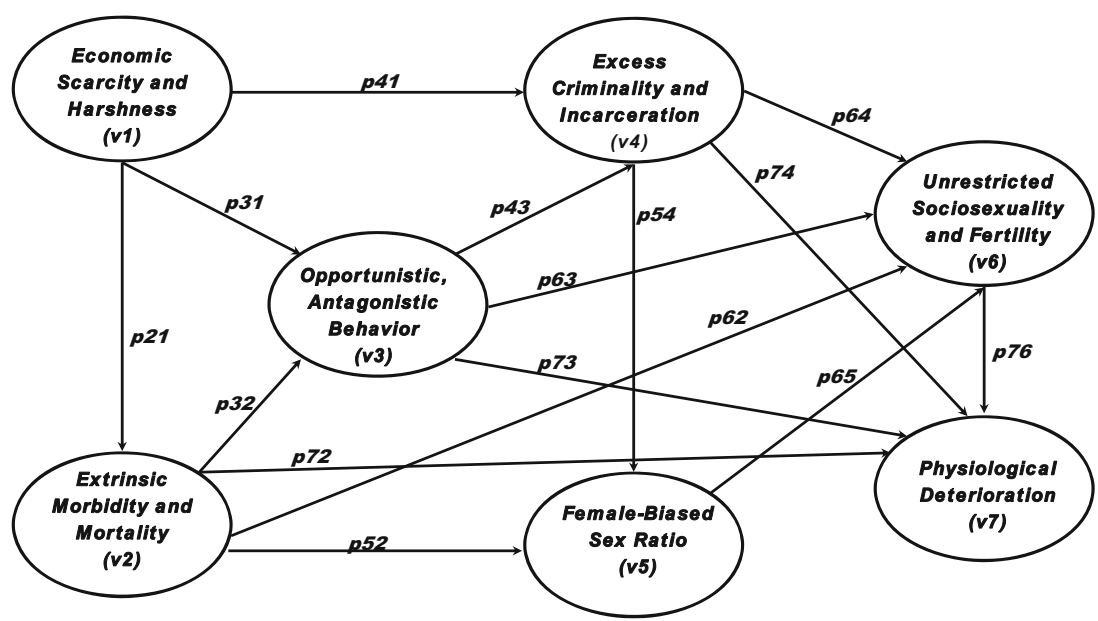

Fig. 1 Conceptual schematic of the cumulative causal influences of harshness and unpredictability in disadvantaged families

Economic Scarcity and Harshness (v1) These represent the double hardships caused by the combination of discrimination and prejudice experienced by ethnic minorities in the United States and the reduction in the availability of resources (including quality education and employment) allocated to them by the social system. Ethnicity and poverty are highly confounded in the United States, disproportionately increasing the chances that members of ethnic minorities are exposed to increased levels of harshness and unpredictability. Minority Stress models (Meyer 2003) posit that disadvantaged groups have been chronically exposed to higher levels of stress in addition to stressors unique to marginalized groups (e.g., stigma and discrimination), such as institutional barriers that impede or deprive minorities of social mobility, access to healthcare or basic necessities. That is, disadvantaged families consistently experience both the "insult" and the "injury" associated with lower socioeconomic status. As Figueredo (2001, p. 232) put it: "It might be the profound social insult, and not the mere physical injury, that distinguishes survivors of social victimization".

We can divide these components conceptually in more commonly accessible language as consisting of: (1) the injury, meaning the actual chronic and sustained material deprivation in terms of physical resources needed for optimal somatic and reproductive development; and (2) the insult, meaning the associated psychological and physiological harm that the psychosocial implications of this deprivation might have for the child's social status in a hierarchically-structured society (e.g., threats to social-self; Dickerson et al. 2004). The majority of the work reviewed here addresses the adverse material effects of low-resource environments and recognition of structural barriers and discrimination that maintain these inequities. The mechanism implied is one of chronic (and often intergenerationally sustained) absolute resource deprivation, whereas relative resource deprivation, the inequitable societal allocation of whatever resources are available among individuals or social groups based on their relative social dominance, rank, or status, is well-documented in social psychology, sociology, and economic theory.

Resource discrepancies coupled with stressors stemming from discrimination should thus increase the level of ecological harshness experienced by minority populations. As 
a result of these harsh and unpredictable conditions, allocation of resources among alternative behaviors, including intense competition, increased violence, and earlier reproduction, were prioritized over developmental timeframes.

As an illustration, African Americans have been shown to experience high levels of resource scarcity resulting from longstanding institutional barriers (Williams 1999; Williams et al. 2010). The median income gap between African American and European American households widened in 2007(African Americans, \$33,916; European Americans, \$52,115; US Census Bureau 2008), resulting in the largest recorded income discrepancy between minority and majority groups since the government began collecting data over 25 years ago (Pew Research Center 2011, p. 1). Households most affected during this time were African American (e.g., Irvin Painter 2007). Family quality of life is directly impacted by economic disadvantage and indirectly influences a child's immediate environment (Bronfenbrenner 1979; Yoshikawa et al. 2012) through increasing unpredictability (e.g., unstable households and neighborhoods) and increased exposure to conditions of extrinsic morbidity and mortality (e.g., homicide, early adult illness/death). Low-income neighborhoods include individuals who cannot afford to own their homes, whose tenuous connections to the labor market or reliance on low-wage jobs with high rates of turnover lead to unstable monthly incomes that often result in multiple moves and unstable households. These unstable and very low incomes are probably responsible for the low rates of home ownership and also leave individuals vulnerable to the impact of unexpected costs such as illness (e.g., extrinsic morbidity).

Extrinsic Morbidity and Mortality (v2) Economic scarcity and harshness contribute directly to extrinsic morbidity and mortality in socially disadvantaged populations (p21; Adler and Stewart 2010; Braveman et al. 2011; Chen et al. 2002). As a result, African Americans, in comparison to European Americans, experience a lower life expectancy - with male life expectancy at 71.7 years (versus 76.4 for European American males) and female life expectancy at 77.8 years (versus 81.1 for European American females) (Kochanek et al. 2015).

Opportunistic, Antagonistic Behavior (v3) Resource-scarce and unpredictable ecologies produce opportunistic, exploitative, and antagonistic interpersonal strategies (p31; Belsky et al. 1991; Figueredo and Jacobs 2010). Disadvantage arising from institutional barriers and inequitable distribution of resources create an environment that should bias developmental allocation toward socially problematic behaviors to acquire status, resources, and access to reproductive partners. For example, some adolescents who grew up in unstable neighborhoods and households are more likely engage with delinquent peers and to engage in risky, antisocial activities (reviewed in Moffitt 1993). Dishion et al. (2012) found an association between a harsh adolescent environment, characterized by poverty, low familial support, and peer marginalization, and the influence of delinquent peers during late adolescence. The study by Dishion et al. (2012) is an empirical example of how environmental harshness may orient individuals toward antagonistic social strategies. Research on environmental harshness and unpredictability has been extended by other researchers to include related factors, such as unstable households and discrimination (e.g., Roberts et al. 2012).

Extrinsic morbidity and mortality contribute directly to opportunistic, exploitative, and antagonistic interpersonal strategies in socially disadvantaged populations (p32). 
According to Ellis et al. (2009) "the most salient feature of low SES environments should be exposure to cues indicating high risk of premature disability or death" (p. 245). Exposure to cues such as deaths or incapacitation of young relatives and peers through violence (directly or indirectly) and/or residing in high crime areas impact the social strategies pursued by individuals (Ellis et al. 2009). Elementary school children exposed to neighborhood or community violence show an increase in aggressive behavior (Guerra et al. 2003), depression (Quiroga et al. 2015), and increased risk of failing a grade (Caudillo and Torche 2014).

Additionally, exposure to household conflict, parental harshness, neglect, or low responsiveness also impact social strategies (Chisholm 1993). In a sample of Mexican children residing in protective services, for example, exposure to family violence, which included violence they experienced or witnessed, directly predicted increased psychological problems such as anxiety and depression, and behavioral issues, measured by alcohol consumption and antisocial delinquent behavior (Frías Armenta and Gaxiola Romero 2008). Psychological and behavioral issues predicted poor performance in school. Emergence of opportunistic, antagonistic behaviors resulting from low parental effort appears to occur early in development. Externalizing behaviors in boys at 2 and 3 years was associated with low maternal responsiveness when the child was 12 months old (Shaw et al. 1998). Early childhood externalizing behavior problems often persist into childhood and adolescence (Angold and Egger 2007; Egeland et al. 1996).

Excess Criminality and Incarceration (v4) Economic scarcity and harshness produces excess criminality and incarceration in various socially disadvantaged populations (p41), but this occurs through a variety of mediating pathways. For example, the intensified competition for status and resources occasioned by resource deprivation has been proposed to perpetuate male violence and incarceration by emphasizing hyper-masculinity as a cultural ideal as indicated by extreme violence and competition (p43; Sampson and Wilson 1995). In relation to the "insult" rather than the "injury" described above, experimental studies demonstrate that African American men who experience lab-induced racial discrimination also increase compensatory masculine displays, operationalized as push-ups, compared to European American men (Goff et al. 2012). The consequences of hyper-masculinity result in perpetuating a cycle of resource inequality, low social mobility, and high rates of incarceration (Irvin Painter 2007; Sampson and Wilson 1995). Additionally, the perceptions of future life uncertainty and perceptions of early mortality perpetuate delinquency and criminal offending trajectories (Caldwell et al. 2006; Piquero 2016). This thus produces a very negative link between violent crimes like homicide and male life expectancy $(r=.88$; Wilson and Daly 1997).

Female-Biased Sex Ratio (v5) Behavioral ecology highlights the importance of sex ratios of viable mates in organizing mating strategies between males and females. Two ratios must be considered: (1) the operational sex ratio (OSR), which is the ratio of males to females ready to mate (Kvarnemo and Ahnesjo 1996) and (2) adult sex ratio (ASR) which is the ratio of sexually mature males to females. Based on the stressful conditions described above, African American males experience excess mortality (Kruger et al. 2013b), the highest proportion of imprisonment in the United States, 
and underrepresentation in higher education (Irvin Painter 2007; Pettit and Western 2004). As a result of both this excess morbidity and mortality (p52) and the high degree of male incarceration ( $\mathbf{p 4}$ ), the sex ratio is biased toward a higher availability of African American women than men in the marriage market (Irvin Painter 2007).

In support of this perspective, Sampson and Wilson (1995) underscore the value of considering context as a key risk factor for criminal behavior, by recommending that behavior should be viewed:

From contextual lenses that highlight the very different ecological contexts that blacks and whites reside in - regardless of individual characteristics. The basic thesis is that macro-social patterns of residential inequality give rise to the social isolation and ecological concentration of the truly disadvantaged, which in turn leads to structural barriers and cultural adaptations that undermine social organization and hence the control of crime (Sampson and Wilson 1995, p. 38).

The arguments presented by Sampson and Wilson (1995) are consistent with evolutionary reasoning: in female-biased versus male-biased environments, the variance of male mating behavior is higher. Accordingly, the unbalanced distribution of resources results in a vicious cycle; felons, in some states, lose the right to vote (either for several years or for life), are disqualified from quality of life programs such as public housing, public assistance, or jobs, stymieing status and opportunities for African American men and their families to escape from poverty (Slopen and Williams 2010). Thus, underrepresentation in higher education may also contribute to the opportunistic and antagonistic behavior patterns that characterize alternative strategies of competition for status resources, and also indirectly lead to more female-biased sex ratios in terms of the number of African-American males that are considered "eligible" as marriage prospects.

Our conceptual schematic posits that criminal behaviors should produce femalebiased sex ratios through incarceration and mortality; however, it should be acknowledged that the causal direction between the variables could be reversed, implying a bidirectional relationship. Female-biased countries and communities experience higher levels of violence, including youth assaults (Kruger et al. 2013a; b) and murder (Barber 2009).

Unrestricted Socio-Sexuality and Fertility (vo) The ecological factors present in impoverished neighborhoods were briefly highlighted in the discussion above, specifically emphasizing harshness, unpredictability, and adult male extrinsic mortality. For example, female-biased sex ratios promote the evolution and development of unrestricted sociosexual strategies and increased fertility (p65). Evolutionary reasoning states that the "rarer" sex would have more sexual control over the mating market. This means that in female-biased communities, men would "control" the mating market, emphasizing the allocation of time and bioenergetic resources toward mating effort than long-term relationships (Kokko and Jennions 2008). Women, in response, would adjust their mating expectations and settle for lower-investing males (Barber 2003; Kruger and Schlemmer 2009).

Based on this hypothesis, researchers have found evidence that female-biased areas increase the likelihood of early births (Barber 2000; Uggla and Mace 2015), and 
increase the proportion of single-mother households (Kruger and Vanas 2012). Consistent with this work, African American women in economically disadvantaged communities report perceiving a disjunction between child-bearing and marriage, and report that having children at an earlier age is an optimal option (Burton 1990; Geronimus 1996). Women relied on the assistance of their mothers to consolidate resources and to assist in direct care of the children because women could not rely on male assistance (Burton 1990; Geronimus 1996). This means that women would conceive earlier to capitalize on the immediate support and resources present in the environment such as "helpers at the nest." Maternal grandmothers frequently serve as alloparents in African American communities, caring for their daughter's children. Further supporting this argument, based on the statistics by The Guttmacher Institute ( 2012), African Americans between 15 and 19 have the highest rates of pregnancy - followed by Latinas. In 2006, the average age of first birth for African American women was 22.7, the second lowest average age for an ethnic group (Native Americans' average age of first birth was 21.9; Center for Disease Control 2009).

Exposure to death, illness, and disability that is independent of health status and age is a key ecological signal that forecasts that future ecological conditions may continue to be harsh, uncontrollable, and unpredictable and/or that one's health and lifespan may deteriorate rapidly (Nettle et al. 2013). As such, exposure to extrinsic morbiditymortality would directly calibrate reproductive strategies and fertility (p62; Stearns 1992). Subjective life expectancy, estimating the age you will live, is one way to gauge one's perception of their future. Not surprisingly, those who report increased economic hardship, diminished hope for the future, and lower educational attainment perceive their lives to be shorter (Mirowsky and Ross 2000). Contextual factors that directly tie to exposure to death and illness such as the premature death of a parent also predicted perception of a shortened life (Denes-Raj and Ehrlichman 1991).

In regards to early cues of extrinsic morbidity and mortality, there is evidence for ecological impact on reproductive factors. Reports of early household stress (up to age 10) were associated with earlier menarche and age of first birth (Chisholm et al. 2005). Evidence for tracking of internal states of health (internal predictive adaptive response; Nettle et al. 2013), also impacts reproduction. Individuals with a history of lifethreatening childhood chronic disease had earlier age of first birth in comparison to those who did not (Waynforth 2012).

The "social norms" of acceptable and unacceptable behavior is dependent on the peer groups that individuals fraternize with. Interacting with "delinquent" peers would condone deviant behaviors such as aggression or risky sex (p63; Dishion and Dodge 2005). Associating with delinquent peers during late adolescence increases conduct problems and sexual risk-taking behaviors (Dishion et al. 2012). Further, both sexual risk-taking and conduct problems were moderately correlated $(r=.29)$, suggesting that environmental harshness may contribute to a cohesive strategy that involves both criminal and risky behaviors (p64). Discrimination experienced by African American youth during middle childhood, has been shown to impact sexual attitudes and risky sexual behavior three years later (Roberts et al. 2012). The association between perceived discrimination and risky sex was mediated by deviant peer affiliation, negative affect and positive attitudes toward sex, suggesting that the negative emotional sequelae of discrimination may cause youth to seek peers who engage and condone 
deviant behavior such as risky sex. The study further found that attentive parenting reduced deviant peer affiliation and decreased positive attitudes toward risky sex.

Physiological Deterioration (v7) The research reviewed documents significant health and physical disparities that exist between majority and minority populations. African Americans, in comparison to European Americans, develop faster and physically deteriorate at an earlier age, even when controlling for socioeconomic status and access to healthcare (Irvin Painter 2007; Williams 1999). While associations between ethnicity and health have been attributed to SES, researchers have begun to investigate possible mechanisms for SES-related early health deterioration (Adler and Stewart 2010). Most obviously, an environment affording elevated levels of extrinsic morbidity and mortality is a major direct cause of physiological deterioration (p72). Considerable research (reviewed in Juster et al. 2011 and Taylor et al. 2011) documents positive associations between early exposure to stressors (e.g., low SES, childhood maltreatment, social isolation) and chronic degenerative disease in adulthood (Lehman et al. 2005; Shonkoff et al. 2009).

According to the weathering hypothesis (Geronimus 1992, 1996; Geronimus et al. 2010), African American women strategically follow an "alternative life-course strategy" that involves early motherhood, accelerating their reproductive output in anticipation of the premature biological degradation. This acceleration starts early; African American girls start puberty earlier than European American girls, at varying economic strata (Braithwaite et al. 2009; Deardoff et al. 2011). In turn, it is also the case that the unrestricted sociosexuality and fertility so produced have marked effects upon further accelerating the physiological deterioration of individuals who are engaging in elevated levels of mating and parental effort (p76). For example, recent experimental work has examined the effects of stress on ideal age of marriage and first birth. Women exposed to the cold-pressor task reported an earlier ideal age of marriage and first birth in comparison to control women exposed to warm water. Further, the experimenters found a significant interaction whereby women exposed to the cold pressor task and reporting higher levels of early adversity reported lower ideal ages of marriage and first birth compared to women who reported lower levels of adversity (Chipman and Morrison 2015).

One possible mechanism for long-term deterioration is the secretion of inflammatory markers, such as cytokines. When inflammatory markers are chronically secreted due to injury or illness, the organism incurs somatic deterioration. Somatic deterioration over time leads to chronic degenerative diseases such as cardiovascular disease (Albert and Ridker 1999; Ridker et al. 2000), diabetes (Pradhan et al. 2001), and others (Juster et al. 2011). Evidence for this mechanism has been found with early environmental stress. Individuals who reported growing up in lower socioeconomic environments were more likely to report higher levels of childhood family dysfunction (Taylor et al. 2006). Childhood family dysfunction was associated with diminished adult psychosocial functioning; lower psychosocial functioning led to an increase in CRP, indicating increased systemic inflammation (Taylor et al. 2006).

Inter-sexual competition (males attracting females) and intra-sexual competition (competing among males for mates) in males requires maintenance of somatic muscularity (i.e., broad shoulders, lean muscle mass increase and adipose tissue decrease), shunting resources away from immune function (Muehlenbein and Bribiescas 2010). Androgens responsible for anabolic mass are also immunosuppressive, diverting 
resources toward mating effort and away from parenting and somatic effort. Research suggesting testosterone's role in shifting male reproductive strategies from mating to parenting finds that pair-bonded males have lower levels of testosterone than single males, (Burnham et al. 2003; Gray et al. 2002). Further, testosterone reactivity experimentally induced through erotic videos negatively correlates to interests in babies (Zilioli et al. 2016). Slow life history in men is associated with an increase interest in babies (Zilioli et al. 2016), while short term mating orientation in men is associated with a decrease in tenderness toward babies (Beall and Schaller 2014). Higher testosterone in the short term may benefit men in acquiring mates but in the long term may contribute to cancers of male reproductive systems, such as prostate cancer (Alvarado 2013).

Excess criminality and incarceration also takes a physiological toll $(\boldsymbol{p} 74)$, as well as the higher degree of dangerous risk-taking behavior entailed in opportunistic and antagonistic behaviors (p73). Criminal offenders have higher odds of succumbing to extrisinc and intrinsic morbidity-mortality in comparison to non-criminal offenders (Nieuwbeerta and Piquero 2008; Zlodre and Fazel 2012). Higher risk of metabolic syndrome has been found in individuals with lower levels of conscientiousness, an indicator of slower LH strategy (Sutin et al. 2010). Further, participants reporting higher levels of impulsiveness and hostility were more likely to have metabolic syndrome (Sutin et al. 2010). The association between "cognitive, affective and behavioral components of hostility" and markers of inflammation were examined in middle-aged European American and African American populations, revealing associations between the three components of hostility (Marsland et al. 2008, p. 754). Analyses that further controlled for trait negative affect revealed that hostile behavior was associated with higher levels of IL-6 and CRP, suggesting that antagonistic behavioral components of fast life history strategies impact future health (Marsland et al. 2008).

\section{Conclusion: Adaptive Calibration to Environmental Stress}

This review has focused on psychosocial and physiological processes that transpire in the organism as a response to ecological parameters presented during development. These associations presented in the current review broadly display how ecological factors can produce specific outcomes in the organism, illuminating to epidemiologists how such physiological changes are functional (Ellis et al. 2009, 2013). The majority of social scientists focus on the behavior and/or cognitions of individuals within numerous contexts (i.e., environment, situation, culture, etc.), but often remain agnostic about the functional role the behavior plays within the context (Cabeza de Baca and Jordan 2012; King and Cabeza de Baca 2011). We thus propose that researchers who focus on the pathophysiology of somatic deterioration consider the unique pathway of reproductive effort when considering research, policy, and clinical implications. By examining in some detail the case of disadvantaged families, we have illustrated how this approach provides new, insightful, and provocative research hypotheses that could inform the etiology of chronic degenerative disease. This review articulated how contextual factors such as socioecological stressors may alter sociocognitive schemata and socioemotional functioning, reproductive behaviors, and, ultimately, longevity. 
The goal of the current article was to highlight the importance of environmental factors on the emergence of life history strategies and adult degenerative disease. While possible environmental mechanisms that create and perpetuate health disparities were outlined, it must be acknowledged that individual differences may not necessarily emerge through shared environmental pathways (Rowe 1994). Nonetheless, we argue, as others have argued (e.g., Turkheimer et al. 2003) that amelioration of contextual factors may modulate development and longevity. Through sophisticated structural equation analyses of longitudinal and nationally representative data show evidence for heritability of life history strategies, there was nevertheless a substantial amount of unique environmental variance estimated in the model (Figueredo et al. 2014). There is hope for amelioration.

Short term modification and activation of physiological systems are functional and contribute toward an optimal allocation and response to ecological stressors. Mechanistic reconfiguration of stress and reproductive systems should lead to strategic modifications (i.e., conditional adaptations; Del Giudice et al. 2011 that shape an organism's developmental trajectory from the womb to the grave. These changes incur long-term costs on the individual, contributing to higher levels of somatic "wear-and-tear" and decreased longevity. But, according to Ellis and Del Giudice (2014), that is only half of the story:

The other half of the story is the coherent, functional responses to stress, including regulation of alternative life history strategies, that reliably emerge in given developmental contexts. These responses have to be taken into account to more fully and accurately capture child and adolescent development under conditions of psychosocial stress and unpredictability (p. 15).

The empirical data reviewed illustrate linkages between early environmental stressors (harshness, unpredictability, high extrinsic morbidity-mortality) and allocation of reproductive effort in humans. The categorization of social discrimination into the facets of harshness and unpredictability should be further studied and clarified. It appears that unique aspects of social discrimination may be components of and contributors to both harshness and unpredictability. At the group level, social discrimination may contribute to harsh ecologies based on structural barriers and disproportionate distribution of resources and opportunities. That is, "discrimination not only limits the quantity of resources available to a particular group but also places limits on their access to those resources," (García Coll et al. 1996, p. 1900). At the individual level, discrimination can manifest as "micro-stressors" fueled by "ambiguity," "unpredictability," and "uncontrollability" (Scott 2003, p. 524). Despite the lack of conceptual clarity, the empirical implications are clear. Childhood experiences regulate reproductive ontogeny to match ecological conditions. Higher levels ecological stress should cause humans to minimize somatic effort in order to invest more in reproductive effort, leading toward a faster life history strategy.

If the disadvantaged children and adolescents, as well as the victimized women, are adapting their behavior consistently with the demands of the harsh and unpredictable environments in which they actually live, then perhaps what is in need of treatment are not their adaptive responses to adversity, but the condition of adversity itself that are presumably triggering those responses. In other words, the cause rather than the symptoms should be the focus of intervention. 


\section{Public Health Policy Implications}

One clear implication of applying LH to ameliorate health disparities is a change in approaches to interventions and policies that are often focused on individual behaviors. LH theory implies that we should focus instead on reducing exposures to the risky early environments that individuals adapt to over development. Such changes in exposure are needed to achieve long-term improvements in health. If individuals are adapting to environmental circumstances, particularly those related to harshness and unpredictability, then intervening to improve those environments rather than the behavioral and physiological adaptations themselves (e.g., early reproduction, antisocial behaviors, poorer immune function) is likely to be more successful in the short and long run.

In recent years, evolutionary-minded think tanks (e.g., evolution-institute.org), interventionists (Wilson et al. 2013), and evolutionary-developmental scientists (Ellis et al. 2012) have argued for context-based interventions that mitigate "deleterious" or "risky" behavior by altering the condition and social norms of the environment in which the individual currently resides. They assert that well-implemented interventions should consider the function of risky behavior and recognize that risky behavior may serve to satisfy evolutionarily-based needs like status attainment (see Kenrick et al. 2010, for a discussion and evolutionary interpretation of Maslow's Hierarchy of Needs). By posing the question of "what's in it" for the individual, researchers will be able to make informed and context-appropriate decisions on how to divert risky behavior toward prosocial means that still fulfill the socioecological needs of the individuals targeted by the intervention (Ellis et al. 2012, p. 615).

Policy should also focus on ameliorating resource disadvantage between individuals or groups of individuals by providing equitable access to institutions that could improve quality of life (e.g., neighborhood access to public transportation, access to high quality education and employment). Fair institutional access will limit socioeconomic discrepancy between groups and directly and indirectly improve quality of life. Past research has shown that paternal job loss and economic stressors can indirectly impact the family environment by altering father-child and father-mother relationships (McLoyd 1989; McLoyd et al. 2006). Thus, income and socioeconomic stability, obtained through more equitable access to resources, can improve the lives of disadvantaged families (e.g., Colen et al. 2006; Costello et al. 2003; see Ellis et al. 2012 for an indepth discussion).

Acknowledgments TCDB was partially supported by a National Institute of Mental Health grant T32MH019391. The authors would like to thank the two anonymous reviewers for their insightful comments and suggestions on earlier drafts of the paper.

\section{References}

Adler, N. E., \& Stewart, J. (2010). Health disparities across the lifespan: Meaning, methods, and mechanisms. Annals of the New York Academy of Sciences, 1186, 5-23.

Alan Guttmacher Institute. (2012) http://www.guttmacher.org/pubs/FB-ATSRH.pdf

Albert, M. A., \& Ridker, P. M. (1999). The role of C-reactive protein in cardiovascular disease risk. Current Cardiology Reports, 1(2), 99-104. 
Alexander, R. D. (1974). The evolution of social behavior. Annual Review of Ecology and Systematics, 5, 325-383.

Alvarado, L. C. (2013). Do evolutionary life-history tradeoffs influence prostate cancer risk? A review of population variation in testosterone levels and prostate cancer disparities. Evolutionary Applications, 6 , 117-133.

Angold, A., \& Egger, H. L. (2007). Preschool psychopathology: lessons for the lifespan. Journal of Child Psychology and Psychiatry, 48, 961-966. doi:10.1111/j.1469-7610.2007.01832.x.

Barber, N. (2000). On the relationship between country sex ratios and teen pregnancy rates: a replication. Cross Cultural Research, 34(1), 26-37.

Barber, N. (2003). Paternal investment prospects and cross-national differences in single parenthood. CrossCultural Research, 37(2), 163-177.

Barber, N. (2009). Countries with fewer males have more violent crime: marriage markets and mating aggression. Aggressive Behavior, 35(1), 49-56.

Beall, A. T., \& Schaller, M. (2014). Affective implications of the mating/parenting trade-off: short-term mating motives and desirability as a short-term mate predict less intense tenderness responses to infants. Personality and Individual Differences, 68, 112-117.

Belsky, J. (2012). The development of human reproductive strategies: progress and prospects. Current Directions in Psychological Science, 21(5), 310-316.

Belsky, J., Steinberg, L., \& Draper, P. (1991). Childhood experience, interpersonal development, and reproductive strategy: an evolutionary theory of socialization. Child Development, 62, 647-670.

Belsky, J., Schlomer, G. L., \& Ellis, B. J. (2012). Beyond cumulative risk: distinguishing harshness and unpredictability as determinants of parenting and early life history strategy. Developmental Psychology, $48,662-673$.

Bjorklund, D. F., \& Ellis, B. J. (2014). Children, childhood, and development in evolutionary perspective. Developmental Review, 34, 225-264.

Blum, S. C., Silver, R. C., \& Poulin, M. J. (2014). Perceiving risk in a dangerous world: associations between life experiences and risk perceptions. Social Cognition, 32(3), 297-314.

Braithwaite, D., Moore, D. H., Lustig, R. H., Epel, E. S., Ong, K. K., Rehkopf, D. H., Wang, M. C., Miller, S. M., \& Hiatt, R. A. (2009). Socioeconomic status in relation to early menarche among black and white girls. Cancer Causes \& Control, 20, 713-720.

Braveman, P. A., Cubbin, C., Egerter, S., Williams, D. R., \& Pamuk, E. (2011). Socioeconomic disparities in health in the United States: what the patterns tell us. American Journal of Public Health, S1, S186-S196. doi:10.2105/AJPH.2009.166082.

Bronfenbrenner, U. (1979). The ecology of human development: experiments by nature and design. Cambridge, MA: Harvard University Press.

Brumbach, B. H., Figueredo, A. J., \& Ellis, B. J. (2009). Effects of harsh and unpredictable environments in adolescence on development of life history strategies: a longitudinal test of an evolutionary model. Human Nature, 20, 25-51.

Burnham, T. C., Chapman, J. F., Gray, P. B., McIntyre, M. H., Lipson, S. F., \& Ellison, P. T. (2003). Men in committed, romantic relationships have lower testosterone. Hormones and Behavior, 44(2), 119-122.

Burton, L. M. (1990). Teenage childbearing as an alternative life-course strategy in multigeneration black families. Human Nature, 1(2), 123-143.

Cabeza de Baca, T., \& Jordan, A. C. (2012). To know is not to love: cognitive and affective barriers toward the adoption of evolutionary theory. Personality and Individual Differences, 58, 681-686.

Cabeza de Baca, T., Barnett, M. A., \& Ellis, B. J. (2016). The development of the child unpredictability schema: the correlates of maternal life history tradeoffs on reproductive effort. Evolutionary Behavioral Sciences, 10, 43-55.

Caldwell, R. M., Wiebe, R. P., \& Cleveland, H. H. (2006). The influence of future certainty and contextual factors on delinquent behavior and school adjustment among African American adolescents. Journal of Youth and Adolescence, 35(4), 587-598.

Caudillo, M. L., \& Torche, F. (2014). Exposure to local homicides and early educational achievement in Mexico. Sociology of Education, 87(2), 89-105.

Center for disease control. (2009) http://www.cdc.gov/nchs/data/databriefs/db21.pdf

Charnov, E. L. (1993). Life history invariants. Oxford: Oxford University Press.

Chen, E., Matthews, K. A., \& Boyce, W. T. (2002). Socioeconomic differences in children's health: how and why do these relationships change with age? Psychological Bulletin, 128, 295-329.

Chipman, A., \& Morrison, E. (2015). Experimentally induced stress decreases ideal female reproductive timing. Psychoneuroendocrinology, 62, 89-95. 
Chisholm, J. S. (1993). Death, hope, and sex: life-history theory and the development of reproductive strategies. Current Anthropology, 34, 1-12.

Chisholm, J. S., Quinlivan, J. A., Petersen, R. W., \& Coall, D. A. (2005). Early stress predicts age at menarche and first birth, adult attachment, and expected lifespan. Human Nature, 16(3), 233-265.

Clancy, K. B. H., Klein, L. D., Ziomkiewicz, A., Nenko, I., Jasienska, G., \& Bribiescas, R. G. (2013). Relationships between biomarkers of inflammation, ovarian steroids, and age at menarche in a rural Polish sample. American Journal of Human Biology, 25, 389-398.

Colen, C. G., Geronimus, A. T., \& Phipps, M. G. (2006). Getting a piece of the pie? The economic boom of the 1990s and declining teen birth rates in the United States. Social Science \& Medicine, 63(6), 15311545 .

Costello, E. J., Compton, S. N., Keeler, G., \& Angold, A. (2003). Relationships between poverty and psychopathology: a natural experiment. JAMA, 290, 2023-2029.

Deardoff, J., Ekwaru, J. P., Kushi, L. H., Ellis, B. J., Greenspan, L. C., Mirabedi, A., Landaverde, E. G., \& Hiatt, R. A. (2011). Father absence, body mass index, and pubertal timing in girls: differential effects by family income and ethnicity. Journal of Adolescent Health, 48, 441-447.

Del Giudice, M., Ellis, B. J., \& Shirtcliff, E. A. (2011). The adaptive calibration model of stress responsivity. Neuroscience and Biobehavioral Reviews, 35, 1562-1592.

Del Giudice, M., Gangestad, S. W., \& Kaplan, H. S. (2015). Life history theory and evolutionary psychology. In D. M. Buss (Ed.), Handbook of evolutionary psychology (pp. 88-114). Hoboken, NJ: Wiley.

Denes-Raj, V., \& Ehrlichman, H. (1991). Effects of premature parental death on subjective life expectancy, death anxiety, and health behavior. OMEGA Journal of Death and Dying, 23(4), 309-321.

Dickerson, S. S., Gruenewald, T. L., \& Kemeny, M. E. (2004). When the social self is threatened: shame, physiology, and health. Journal of Personality, 72(6), 1191-1216.

Dishion, T. J., \& Dodge, K. A. (2005). Peer contagion in interventions for children and adolescents: moving towards an understanding of the ecology and dynamics of change. Journal of Abnormal Child Psychology, 33(3), 395-400.

Dishion, T. J., Ha, T., \& Véronneau, M.-H. (2012). An ecological analysis of the effects of deviant peer clustering on sexual promiscuity, problem behavior, and childbearing from early adolescence to adulthood: an enhancement of the life history framework. Developmental Psychology, 48, 703-717.

Doom, J. R., Vanzomeren-Dohm, A. A., \& Simpson, J. A. (2015). Early unpredictability predicts increased adolescent externalizing behaviors and substance use: A life history perspective. Development and psychopathology. DOI: http://dx.doi.org/10.1017/S0954579415001169

Egeland, B., Pianta, R., \& Ogawa, J. (1996). Early behavior problems: pathways to mental disorders in adolescence. Development and Psychopathology, 8(04), 735-749.

Ellis, B. J. (2004). Timing of pubertal maturation in girls: an integrated life history approach. Psychological Bulletin, 130, 920-958.

Ellis, B. J. (2013). The hypothalamic-pituitary-gonadal axis: a switch-controlled, condition-sensitive system in the regulation of life history strategies. Hormones and Behavior, 64(2), 215-225.

Ellis, B. J., \& Del Giudice, M. (2014). Beyond allostatic load: rethinking the role of stress in regulating human development. Development and Psychopathology, 26, 1-20.

Ellis, B. J., Bates, J. E., Dodge, K. A., Fergusson, D. M., John Horwood, L., Pettit, G. S., \& Woodward, L. (2003). Does father absence place daughters at special risk for early sexual activity and teenage pregnancy? Child Development, 74, 801-821.

Ellis, B. J., Figueredo, A. J., Brumbach, B. H., \& Schlomer, G. L. (2009). Mechanisms of environmental risk: the impact of harsh versus unpredictable environments on the evolution and development of life history strategies. Human Nature, 20, 204-268.

Ellis, B. J., Del Giudice, M., Dishion, T. J., Figueredo, A. J., Gray, P., Griskevicius, V., et al. (2012). The evolutionary basis of risky adolescent behavior: implications for science, policy, and practice. Developmental Psychology, 48, 598-623.

Ellis, B. J., Del Giudice, M., \& Shirtcliff, E. A. (2013). Beyond allostatic load: the stress response system as a mechanism of conditional adaptation. In T. P. Beauchaine, \& S. P. Hinshaw (Eds.), Child and adolescent psychopathology (2nd ed., ). New York: Wiley \& Sons.

Ellison, P. T., \& Jasienska, G. (2007). Constraint, pathology, and adaptation: how can we tell them apart? American Journal of Human Biology, 19, 622-630.

Figueredo, A. J. (2001). Blame, retribution and deterrence among both perpetrators and survivors of male violence against women. Virginia Journal of Social Policy \& the Law, 8(1), 219-251.

Figueredo, A. J., \& Jacobs, W. J. (2010). Aggression, risk-taking, and alternative life history strategies: the behavioral ecology of social deviance. In M. Frías-Armenta, \& V. Corral-Verdugo (Eds.), Bio-psychosocial perspectives on interpersonal violence (pp. 3-28). Hauppauge, NY: Nova Science Publishers. 
Figueredo, A. J., \& Rushton, J. P. (2009). Evidence for shared genetic dominance between the general factor of personality, mental and physical health, and life history traits. Twin Research and Human Genetics, 12, $555-563$.

Figueredo, A. J., Vásquez, G., Brumbach, B. H., \& Schneider, S. M. R. (2004). The heritability of life history strategy: the K-factor, covitality, and personality. Social Biology, 51, 121-143.

Figueredo, A. J., Vásquez, G., Brumbach, B. H., Schneider, S. M., Sefcek, J. A., Tal, I. R., et al. (2006). Consilience and life history theory: from genes to brain to reproductive strategy. Developmental Review, 26(2), 243-275.

Figueredo, A. J., Vásquez, G., Brumbach, B. H., \& Schneider, S. M. R. (2007). The K-factor, covitality, and personality: a psychometric test of life history theory. Human Nature, 18, 47-73.

Figueredo, A. J., Cuthbertson, A. M., Kauffman, I. A., Weil, E., \& Gladden, P. R. (2012). The interplay of behavioral dispositions and cognitive abilities: sociosexual orientation, emotional intelligence, executive functions, and life history strategy. Temas em Psicologia, 20(1), 81-100.

Figueredo, A. J., Cabeza de Baca, T., \& Woodley, M. A. (2013). The measurement of human life history strategy. Personality and Individual Differences, 55, 251-255.

Figueredo, A. J., Cabeza de Baca, T., \& Black, C. (2014). No matter where you go, there you are: the genetic foundations of temporal stability. Journal of Methods and Measurement in the Social Sciences, 5(2), 76106.

Flinn, M. V. (2006). Evolution and ontogeny of stress response to social challenge in the human child. Developmental Review, 26, 138-174.

Fredrickson, B. L., Grewen, K. M., Coffey, K. A., Algoe, S. B., Firestine, A. M., Arevalo, J. M. G., et al. (2013). A functional genomic perspective on human well-being. Proceedings of the National Academy of Science, 110, 13684-13689.

Frías Armenta, M., \& Gaxiola Romero, J. C. (2008). Consecuencias de la violencia familiar experimentada directa e indirectamente en niños: depresión, ansiedad, conducta antisocial y ejecución académica. Revista Mexicana de Psicología, 25(2), 237-248.

García Coll, C., Lamberty, G., Jenkins, R., McAdoo, H. P., Crnic, K., Wasik, B. H., \& Vásquez García, H. (1996). An integrative model for the study of developmental competencies in minority children. Child Development, 67, 1891-1914.

Garfin, D. R., Silver, R. C., Gil-Rivas, V., Guzmán, J., Murphy, J. M., Cova, F., et al. (2014). Children's reactions to the 2010 Chilean earthquake: The role of trauma exposure, family context, and school-based mental health programming. Psychological Trauma: Theory, Research, Practice, and Policy, 6(5), 563.

Geary, D. C. (2000). Evolution and proximate expression of human paternal investment. Psychological Bulletin, 126, 55-77.

Geary, D. C., \& Flinn, M. V. (2001). Evolution of human parental behavior and the human family. Parenting: Science and Practice, 1, 5-61.

Geronimus, A. T. (1992). The weathering hypothesis and the health of African-American women and infants: evidence and speculations. Ethnicity and Disease, 2, 207-221.

Geronimus, A. T. (1996). What teen mothers know. Human Nature, 7, 323-352.

Geronimus, A. T., Hicken, M., Pearson, J., Seashols, S., Brown, K., \& Dawson Cruz, T. (2010). Do US black women experience stress-related accelerated biological aging? A novel theory and first population-based test of black-white differences in telomere length. Human Nature: An Interdisciplinary Biosocial Perspective, 21, 19-38.

Gladden, P. R., Figueredo, A. J., Andrzejczak, D. J., Jones, D., \& Smith-Castro, V. (2013). Reproductive strategy and sexual conflict: slow life history inhibits negative androcentrism. Journal of Methods and Measurement in the Social Sciences, 4, 48-71.

Gluckman, P. D., Low, F. M., Buklijas, T., Hanson, M. A., \& Beedle, A. S. (2011). How evolutionary principles improve the understanding of human health and disease. Evolutionary Applications, 4(2), 249263.

Goff, P. A., Di Leone, B. A. L., \& Kahn, K. B. (2012). Racism leads to pushups: how racial discrimination threatens subordinate men's masculinity. Journal of Experimental Social Psychology, 48(5), 1111-1116.

Gray, P. B., Kahlenberg, S. M., Barrett, E. S., Lipson, S. F., \& Ellison, P. T. (2002). Marriage and fatherhood are associated with lower testosterone in males. Evolution and Human Behavior, 23(3), 193-201.

Guerra, N. G., Huesmann, L. R., \& Spindler, A. (2003). Community violence exposure, social cognition, and aggression among urban elementary school children. Child Development, 74, 1561-1576.

Hales, C. N., \& Barker, D. J. P. (1992). Type 2 (non-insulin-dependent) diabetes mellitus: the thrifty phenotype hypothesis. Diabetologia, 35, 595-601.

Irvin Painter, N. (2007). Creating black Americans: African-American history and its means, 1619 to the present. New York: Oxford University Press. 
Juster, R.-P., Bizik, G., Picard, M., Arsenault-Lapierre, G., Sindi, S., Trepanier, L., et al. (2011). A transdisciplinary perspective of chronic stress in relation to psychopathology throughout life span development. Development and Psychopathology, 23, 725-776.

Kenrick, D. T., Griskevicius, V., Neuberg, S. L., \& Schaller, M. (2010). Renovating the pyramid of needs: contemporary extensions built upon ancient foundations. Psychological Science, 5, 292-314.

King, A. C., \& Cabeza de Baca, T. (2011). The stagnancy of family studies in modern academia: resistances toward the integration of evolutionary theory. Evolution: Education and Outreach, 4, 64-74.

Kochanek, K. D., Murphy, S. L., \& Xu, J. (2015). Deaths: Final Data for 2011. National vital statistics reports: from the centers for disease control and prevention, national center for health statistics, National Vital Statistics System, 63(3), 1-120, http:/www.cdc.gov/nchs/data/nvsr/nvsr63/nvsr63_03.pdf.

Kokko, H., \& Jennions, M. D. (2008). Parental investment, sexual selection and sex ratios. Journal of Evolutionary Biology, 21(4), 919-948.

Kruger, D. J., \& Schlemmer, E. (2009). Male scarcity is differentially related to male marital likelihood across the life course. Evolutionary Psychology, 7, 280-287.

Kruger, D. J., \& Vanas, S. B. (2012). Local scarcity of women predicts higher fertility among married couples and more single father households. Letters on Evolutionary Behavioral Science, 3, 17-20.

Kruger, D. J., Aiyer, S. M., Caldwell, C. H., \& Zimmerman, M. A. (2013a). Local scarcity of adult men predicts youth assault rates. Journal of Community Psychology, 42, 119-125.

Kruger, D. J., Clark, J., \& Vanas, S. (2013b). Male scarcity is associated with higher prevalence of premature gestation and low birth weight births across the USA. American Journal of Human Biology, 25, 225-227.

Kuzawa, C. W., \& Quinn, E. A. (2009). Developmental origins of adult function and health: evolutionary hypotheses. Annual Review of Anthropology, 38, 131-147.

Kuzawa, C. W., Chugani, H. T., Grossman, L. I., Lipovich, L., Muzik, O., Hof, P. R., et al. (2014). Metabolic costs and evolutionary implications of human brain development. Proceedings of the National Academy of Sciences, 111(36), 13010-13015.

Kvarnemo, C., \& Ahnesjo, I. (1996). The dynamics of operational sex ratios and competition for mates. Trends in Ecology \& Evolution, 11(10), 404-408.

Lehman, B. J., Taylor, S. E., Kiefe, C. I., \& Seeman, T. E. (2005). Relation of childhood socioeconomic status and family environment to adult metabolic functioning in the CARDIA study. Psychosomatic Medicine, 67, 846-854.

Marsland, A. L., Prather, A. A., Petersen, K. L., Cohen, S., \& Manuck, S. B. (2008). Antagonistic characteristics are positively associated with inflammatory markers independently of trait negative emotionality. Brain, Behavior, and Immunity, 22, 753-761.

McDade, T. W. (2003). Life history theory and the immune system: steps toward a human ecological immunology. Yearbook of Physical Anthropology, 46, 100-125.

McDade, T., W. (2005). Life history, maintenance, and the early origins of immune function. American Journal of Human Biology, 17, 81-94.

McLoyd, V. C. (1989). Socialization and development in a changing economy: the effects of paternal job and income loss on children. American Psychologist, 44, 293-302.

McLoyd, V. C., Aikens, N., \& Burton, L. (2006). Childhood Poverty, policy, and Practice. In W. Damon, R. Lerner, A. Renninger, \& I. Sigel (Eds.), Handbook of Child Psychology: Vol. 4. Child Psychology in Practice (6th ed., pp. 700-775). New York: Wiley.

Mendle, J., Ryan, R. M., \& McKone, K. M. (2015). Early childhood maltreatment and pubertal development: replication in a population-based sample. Journal of Research on Adolescence. doi:10.1111/jora.12201.

Meyer, I. H. (2003). Prejudice, social stress, and mental health in lesbian, gay, and bisexual populations: conceptual issues and research evidence. Psychological Bulletin, 129, 674-697.

Mirowsky, J., \& Ross, C. E. (2000). Socioeconomic status and subjective life expectancy. Social Psychology Quarterly, 133-151.

Moffitt, T. E. (1993). Adolescence-limited and life-course-persistent antisocial behavior: a developmental taxonomy. Psychological Review, 100, 674-701.

Muehlenbein, M. P., \& Bribiescas, R. G. (2010). Male reproduction: physiology, behavior, and ecology. In M. P. Muehlenbein (Ed.), Human evolutionary biology (pp. 351-375). Cambridge, UK: Cambridge University Press.

Nettle, D., Frankenhuis, W. E., \& Rickard, I. J. (2013). The evolution of predictive adaptive responses in human life history (p. 280). Proceedings of the Royal Society B: Biological Sciences. doi:10.1098/rspb. 2013.1343.

Nieuwbeerta, P., \& Piquero, A. R. (2008). Mortality rates and causes of death of convicted Dutch criminals 25 years later. Journal of Research in Crime and Delinquency, 45(3), 256-286. 
Olderbak, S. G., \& Figueredo, A. J. (2009). Predicting romantic relationship satisfaction from life history strategy. Personality and Individual Differences, 46, 604-610.

Olderbak, S. G., \& Figueredo, A. J. (2010). Life history strategy as a longitudinal predictor of relationship satisfaction and dissolution. Personality and Individual Differences, 49(3), 234-239.

Pettit, B., \& Western, B. (2004). Mass imprisonment and the life course: race and class inequality in U.S. Incarceration. American Sociological Review, 69, 151-169.

Pew Research Center. (2011). Wealth Gaps rise to Record Highs Between Whites, Blacks, and Hispanics. Retrieved from http://www.pewsocialtrends.org/files/2011/07/SDT-Wealth-Report_7-26-11_FINAL.pdf

Piquero, A. R. (2016). "Take my license n' all that jive, I can't see...35": little hope for the future encourages offending over time. Justice Quarterly, 33, 73-99. doi:10.1080/07418825.2014.896396.

Pradhan, A. D., Manson, J. E., Rifai, N., Buring, J. E., \& Ridker, P. M. (2001). C-reactive protein, interleukin6, and risk of developing type 2 diabetes mellitus. Journal of the American Medical Association, 286, $327-334$.

Quiroga, A., Willis, G. B., López-Rodríguez, L., \& Moreno, A. (2015). Psychological consequences of collective violence in childhood: the case of Monterrey, Mexico. Estudios de Psicología/Studies in Psychology, 36, 294-315. doi:10.1080/02109395.2015.1026122.

Rickard, I. J., Frankenhuis, W. E., \& Nettle, D. (2014). Why are childhood family factors associated with timing of maturation? A role for internal prediction. Perspectives on Psychological Science, 9, 3-15.

Ridker, P. M., Hennekens, C. H., Buring, J. E., \& Rifai, N. (2000). C-reactive protein and other markers of inflammation in the prediction of cardiovascular disease in women. The New England Journal of Medicine, 342, 836-843.

Roberts, M. E., Gibbons, F. X., Gerrard, M., Weng, C. Y., Murry, V. M., Simons, L. G., Simons, R. L., \& Lorenz, F. O. (2012). From racial discrimination to risky sex: prospective relations involving peers and parents. Developmental Psychology, 48, 89-102.

Roff, D. (1992). The evolution of life histories: theory and analysis. New York: Chapman and Hall.

Ross, L. T., \& Hill, E. M. (2002). Childhood unpredictability, schemas for unpredictability, and risk taking. Social Behavior and Personality, 30, 453-474.

Rowe, D. C. (1994). The limits of family influence: genes, experience, and behavior. Guilford Press.

Sampson, R. J., \& Wilson, W. J. (1995). Toward a theory of race, crime, and urban inequality. In J. Hagen, \& R. D. Peterson (Eds.), Race, crime, and justice: A reader (pp. 37-54). Stanford, CA: Stanford University Press.

Scott Jr., L. (2003). The relation of racial identity and racial socialization to coping with discrimination among African American adolescents. Journal of Black Studies, 33, 520-538.

Shaw, D. S., Winslow, E. B., Owens, E. B., Vondra, J. I., Cohn, J. F., \& Bell, R. Q. (1998). The development of early externalizing problems among children from low-income families: a transformational perspective. Journal of Abnormal Child Psychology, 26(2), 95-107.

Shonkoff, J. P., \& Bales, S. N. (2011). Science does not speak for itself: translating child development research for the public and its policymakers. Child Development, 82, 17-32.

Shonkoff, J. P., Boyce, W. T., \& McEwen, B. S. (2009). Neuroscience, molecular biology, and the childhood roots of health disparities: building a new framework for health promotion and disease prevention. Journal of the American Medical Association, 301, 2252-2259.

Simpson, J. A., Griskevicius, V., Kuo, S. I., Sung, S., \& Collins, W. A. (2012). Evolution, stress, and sensitive periods: the influence of unpredictability in early versus late childhood on sex and risky behavior. Developmental Psychology, 48(3), 674.

Slopen, N., \& Williams, D. R. (2010). Improving the Health of Young Men and Boys of Color. In E. C. Jr, \& R. J. d. Velasco (Eds.), Changing Places: How Communities Will Improve the Health of Boys of Color (pp. 311-357). Presented at the Berkeley and Los Angeles, Berkeley and Los Angeles: University of California Press.

Stearns, S. C. (1992). The evolution of life histories. New York: Oxford University Press.

Stearns, S. C., Allal, N., \& Mace, R. (2008). Life history theory and human development. In C. Crawford, \& D. Krebs (Eds.), Foundations of evolutionary psychology (pp. 47-70). New York: Erlbaum.

Sutin Jr., A. R., Costa, P. T., Uda, M., Ferrucci, L., Schlessinger, D., \& Terracciano, A. (2010). Personality and metabolic syndrome. Age, 32, 513-519.

Szepsenwol, O., Simpson, J. A., Griskevicius, V., \& Raby, K. L. (2015). The effect of unpredictable early childhood environments on parenting in adulthood. Journal of Personality and Social Psychology, 109, 1045-1067.

Taylor, S. E., Lehman, B. J., Kiefe, C. I., \& Seeman, T. E. (2006). Relationship of early life stress and psychological functioning to adult C-reactive protein in the coronary artery risk development in young adults study. Biological Psychiatry, 60, 819-824. 
Taylor, S. E., May, B. M., \& Seeman, T. E. (2011). Early adversity and adult health outcomes. Development and Psychopathology, 23, 939-954.

Trivers, R. L. (1972). Parental investment and sexual selection. In Campbell, B., ed., Sexual Selection and the Descent of Man. London: Heinemann, pps. 136-179

Turkheimer, E., Haley, A., Waldron, M., D'Onofrio, B., \& Gottesman, I. I. (2003). Socioeconomic status modifies heritability of IQ in young children. Psychological Science, 14(6), 623-628.

Uggla, C., \& Mace, R. (2015). Local ecology influences reproductive timing in Northern Ireland independently of individual wealth. Behavioral Ecology, arv133.

United States Census Bureau: Current Population Survey (2008). Report on Income, Expenditures, and Wealth. Retrieved from http://www.census.gov/prod/2009pubs/10statab/income.pdf on February 4, 2012

Vigil, J. M., Geary, D. C., \& Byrd-Craven, J. (2005). A life history assessment of early childhood sexual abuse in women. Developmental Psychology, 41(3), 553.

Waynforth, D. (2012). Life-history theory, chronic childhood illness and the timing of first reproduction in a British birth cohort. Proceedings of the Royal Society of London B: Biological Sciences, rspb20120220.

Wight, D., Williamson, L., \& Marion Henderson, M. (2006). Parental influences on young people's sexual behaviour: a longitudinal analysis. Journal of Adolescence, 29, 473-494.

Williams, D. R. (1999). Race, socioeconomic status, and health. The added effects of racism and discrimination. Annals of the New York Academy of Sciences, 896, 173-188.

Williams, D. R., Mohammed, S. A., Leavell, J., \& Collins, C. (2010). Race, socioeconomic status, and health: complexities, ongoing challenges, and research opportunities. Annals of the New York Academy of Sciences, 1186, 69-101.

Wilson, M., \& Daly, M. (1997). Life expectancy, economic inequality, homicide, and reproductive timing in Chicago neighbourhoods. BMJ [British Medical Journal], 314(7089), 1271.

Wilson, D. S., Hayes, S. C., Biglan, A., \& Embry, D. D. (2013). Evolving the future: toward a science of intentional change. Behavioral and Brain Sciences, 1-99.

Yoshikawa, H., Aber, J. L., \& Beardslee, W. R. (2012). The effects of poverty on the mental, emotional, and behavioral health of children and youth: implications for prevention. American Psychologist, 67(4), 272.

Zilioli, S., Ponzi, D., Henry, A., Kubicki, K., Nickels, N., Wilson, M. C., \& Maestripieri, D. (2016). Interest in Babies Negatively Predicts Testosterone Responses to Sexual Visual Stimuli Among Heterosexual Young Men. Psychological Science, 27,114-118

Zlodre, J., \& Fazel, S. (2012). All-cause and external mortality in released prisoners: systematic review and meta-analysis. American Journal of Public Health, 102(12), e67-e75. 